\title{
Pore Structure Control of Ordered Mesoporous Silica Film Using Mixed Surfactants
}

\author{
Tae-Jung Ha, ${ }^{1}$ Hyeon-Gyoon Im, ${ }^{1}$ Seok-Jin Yoon, ${ }^{2}$ Ho Won Jang, ${ }^{2}$ and Hyung-Ho Park ${ }^{1}$ \\ ${ }^{1}$ Department of Materials Science and Engineering, Yonsei University, 134 Sinchon-dong, Seodaemun-gu, \\ Seoul 120-749, Republic of Korea \\ ${ }^{2}$ Electronic Materials Research Center, Korea Institute of Science and Technology, Seoul 130-650, Republic of Korea \\ Correspondence should be addressed to Hyung-Ho Park, hhpark@yonsei.ac.kr
}

Received 23 December 2010; Revised 17 March 2011; Accepted 19 April 2011

Academic Editor: Shaogang Hao

Copyright () 2011 Tae-Jung Ha et al. This is an open access article distributed under the Creative Commons Attribution License, which permits unrestricted use, distribution, and reproduction in any medium, provided the original work is properly cited.

\begin{abstract}
Materials with nanosized and well-arranged pores have been researched actively in order to be applied to new technology fields. Especially, mesoporous material containing various pore structures is expected to have different pore structure. To form a mixed pore structure, ordered mesoporous silica films were prepared with a mixture of surfactant; Brij-76 and P-123 block copolymer. In mixed surfactant system, mixed pore structure was observed in the region of P-123/(Brij-76 + P-123) with about 50.0 wt.\% while a single pore structure was observed in regions which have large difference in ratio between Brij-76 and P-123 through the X-ray diffraction analysis. Regardless of surfactant ratio, porosity was retained almost the same. It is expected that ordered mesoporous silica film with mixed pore structure can be one of the new materials which has distinctive properties.
\end{abstract}

\section{Introduction}

Porous materials are classified into several kinds such as microporous, mesoporous, and macroporous by their pore size according to the IUPAC (International Union of Pure and Applied Chemistry) notation [1]. The microporous materials have pore diameter less than $2 \mathrm{~nm}$, and the macroporous materials have pore diameter greater than $50 \mathrm{~nm}$. The mesoporous materials contain pores with diameter between 2 and $50 \mathrm{~nm}$. They have been still researched since 1970s, and research in this field has steadily grown [2]. They have low density, large surface area, insulating property, and higher elastic modulus than nonordered mesoporous materials. For these properties, it was expected that they can be used in various application fields such as sensor, electronic, membrane, gas storage, adsorbent, catalyst support, and so on [3-5]. Silica-based materials, with nanosized pores, were discovered in 1992 by the researchers of the Mobil Oil Corporation [6]. These materials were first obtained as powders by mixing organic surfactant with silica precursor. Mesoporous thin films have been obtained more recently using the evaporation-induced self-assembly (EISA) method, developed by Lu et al. in 1997 [7]. EISA method is a way to form micelles using surfactant, and a driving force for the formation of micelle is to reduce contact area between hydrocarbon chain and hydrophilic solvent [8]. When the concentration of the solution is below the critical micelle concentration (cmc), surfactant molecules can move around in solution without making micelles [9]. With evaporation of solvent, above $\mathrm{cmc}$, the concentration of solution increases, so surfactant molecules start making micelles. After that, micelles stack up and form an ordered structure, and then finally, ordered mesoporous silica film can be obtained through calcination to remove the organic surfactant. There are several variables of forming ordered mesoporous structure such as reactant concentration, synthesis temperature, $\mathrm{pH}$ of solution, and the nature of surfactant. However, the effects of mixed surfactants on ordered mesoporous silica are hardly known because there have been several researches related with single surfactant, but there have been only few researches with mixed surfactants [10-17]. Lan Chen et al. made their studies on the mixture of various surfactants and synthesized the bimodal structure in P123-P65-25R4 system. But new ordered pore structure was not discovered. Therefore, further research is needed about ordered the mesoporous silica film using mixed surfactant. 


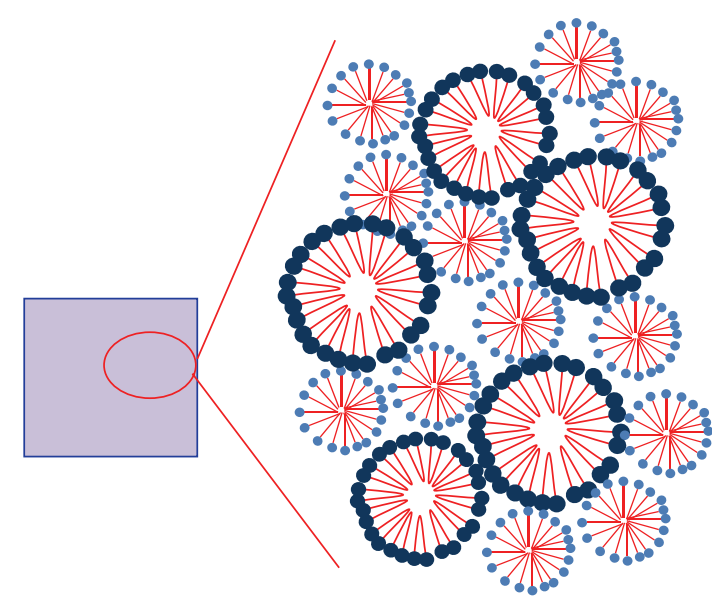

(a)

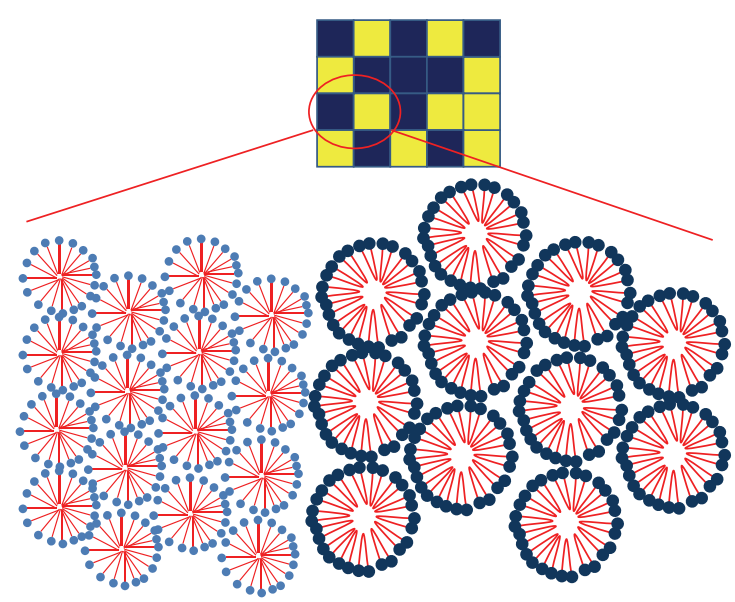

(b)

Figure 1: Possible states of the structure of the micelles; (a) nonseparated state and (b) separated state.

Understanding the correlation between structure and mixed surfactant can be deployed on a commercial scale.

Density of material influences on some of the other physical properties of material. Refractive index, for example, is a kind of property which is related with density of the material. Because mesoporous materials have pores, if we control the pore structures of the mesoporous material intentionally, we can get the material with various densities using mixed surfactants. Thus, we can have the material that has different refractive indices although it is composed entirely of the same chemical species. Through the control of the thickness of regions with different indices, we can modify transmission and reflection of light, and it could be applied to several fields such as high reflective glass and transparent thermal insulating materials. Also, processing steps can be reduced by using mixed surfactant system. There have been several reports about ordered mesoporous silica using surfactant Brij-76 or P-123. According to the researches, Brij-76 is known that it can make $2 \mathrm{D}$ hexagonal, BCC, and lamellar structure, and P-123 is known that it can make 2D hexagonal and BCC structure [18-20].

In this study, mesoporous silica film was obtained using two surfactants, Brij-76 and P-123, with various molar ratios. The pore structure variation according to the molar ratio of the surfactants was analyzed.

\section{Experimental Procedure}

Ordered mesoporous silica films were synthesized by the EISA method as follows. Firstly, EtOH (Duksan, 99.9\%) was used as a solvent. The Brij-76 $\left(\mathrm{C}_{18} \mathrm{H}_{37}\left(\mathrm{OCH}_{2} \mathrm{CH}_{2}\right)_{10} \mathrm{OH}\right.$, Aldrich) and the P-123 block copolymer $\left(\mathrm{H}\left(\mathrm{OCH}_{2} \mathrm{CH}_{2}\right)_{10}\right.$. $\left(\mathrm{OCH}_{3} \mathrm{CH}_{2} \mathrm{CH}_{2}\right)_{70}\left(\mathrm{OCH}_{2} \mathrm{CH}_{2}\right)_{10} \mathrm{OH}$, Aldrich) were dissolved in the solvent, and acidified $\mathrm{H}_{2} \mathrm{O}$ was added. After stirring for $1 \mathrm{~h}$, TEOS (Fluka, 98\%) was sequentially added to the solution as silica precursor. The final molar ratio of TEOS:EtOH: $\mathrm{H}_{2} \mathrm{O}: \mathrm{HCl}:$ mixed surfactants was $1: 20: 5: 0.01: 0.05$, and the weight ratio of the mixed surfactants (P-123/(Brij-76 + P-123)) was changed from 0 to $100 \mathrm{wt} \% \%$ having $12.5 \mathrm{wt} . \%$ interval. After $30 \mathrm{~min}$, a sol was spin-coated on silicon wafers at $3000 \mathrm{rpm}$ for $30 \mathrm{sec}$ at $23^{\circ} \mathrm{C}$ and a relative humidity of $30 \%$. The used silicon wafer is (100)-oriented and its surface is hydrophilic caused by RCA-1 cleaning. To remove the block copolymer, ordered mesoporous silica films were calcined at $400^{\circ} \mathrm{C}$ for $2 \mathrm{~h}$ at a heating rate of $1^{\circ} \mathrm{C} / \mathrm{min}$ in oxygen atmosphere.

To investigate the ordered pore structure, X-ray powderdiffraction (XRD) patterns were collected using $\mathrm{Cu} K \alpha$ radiation with wavelength of $1.5418 \AA$. The porosity of the film was measured by ellipsometry. The microstructural images of the mesoporous silica film were obtained using a transmission electron microscope (TEM, JEOL JEM-4010) at $400 \mathrm{kV}$.

\section{Pore Structure Model}

Two kinds of surfactants, Brij-76 and P-123, are different in several properties. Among them, especially, Brij-76 has lower molecular weight (M.W. of Brij-76 and P-123 are 710 and 5750, resp.), and the chain length of Brij-76 is shorter. As a result, it is expected that the micelle of Brij-76 is smaller than that of P-123, so they can make different pore structures above cmc. Therefore, pore structure synthesized using mixed surfactant which consists of Brij-76 and P123 can be suggested as two models on the assumption that micelles are made by only same the kind of surfactant. They are nonseparated and separated states. Nonseparated state is a state which has a region with randomly mixed micelles, so it has disordered and isotropic pore structure as shown in Figure 1(a). Two kinds of micelles should be formed in similar rates in order to form nonseparated state. Therefore, each surfactant should have similar $\mathrm{cmc}$ in this case. Separated state is a state with the mixture of regions with homogeneously packed micelles, so it can be assembly of ordered pore structures as shown in Figure 1(b). Two kinds of surfactants should have very different $\mathrm{cmc}$ to form 
separated state. We can control pore structures using the rate of the micelle formation in this case. If ordered mesoporous silica film is made by mixed surfactant which consisted of Brij-76 and P-123, it is expected a separated state model due to large difference of $\mathrm{cmc}$ in this report.

\section{Results and Discussion}

Figure 2 shows XRD spectra of ordered mesoporous silica films according to the weight ratio of mixed surfactants (P$123 /($ Brij-76 + P-123)). Only one peak was detected when $\mathrm{P}-123 /($ Brij-76 + P-123) is from 0 to 25.0 and from 75.0 to $100 \mathrm{wt} . \%$. It is the peak of the pore structure formed by Brij76 and appeared at $2.91^{\circ}$ in region of P-123/(Brij-76 + P123) from 0 to $25.0 \mathrm{wt.} \%$ [18]. Also, the d-spacing which means a distance between pores is about $3 \mathrm{~nm}$. In the region of $\mathrm{P}-123 /($ Brij-76 + P-123) from 75.0 to $100 \mathrm{wt} . \%$, the peak is caused by the pore structure formed by P-123 and appeared at $2.26^{\circ}$, and d-spacing corresponds to about $3.9 \mathrm{~nm} \mathrm{[21].}$ That shows the micelle size of $\mathrm{P}-123$ is bigger than that of Brij-76 because that the size of surfactant $\mathrm{P}-123$ is bigger. In case of $\mathrm{P}-123 /($ Brij-76 + P-123) is 12.5, 25.0, 75.0, and $87.5 \mathrm{wt} . \%$, there also was one peak of each, little bit shifted. That means the small amount of minor surfactant hinders making pore structure formed by major surfactant instead of making separated phase. At the point of $50.0 \mathrm{wt} . \%$ of P123/(Brij-76 + P-123), two XRD peaks were observed. That means the ordered mesoporous silica film had mixed pore structure, and each surfactant was enough to make its own pore structure. It can be explained as that Brij-76 has lower $\mathrm{cmc}$ value $(0.002 \mathrm{~g} / \mathrm{L}$ at $298 \mathrm{~K})$ than the $\mathrm{cmc}$ value of $\mathrm{P}$ $123(0.045 \mathrm{~g} / \mathrm{L}$ at $298 \mathrm{~K})$, so micelles of Brij-76 were formed earlier than micelles of P-123 [22, 23]. In addition, seeing that the intensity of the XRD peak formed by Brij-76 is higher than that by $\mathrm{P}-123$, pore structure formed by the micelles of Brij-76 was developed more ordered for the same reason. In case of 37.5 and $62.5 \mathrm{wt} . \%$ in P-123/(Brij-76 + P-123), two XRD peaks were detected, so there existed mixed pore structures in the region from 37.5 to $62.5 \mathrm{wt} . \%$. Therefore, it was expected transition region existed that between 37.5 and $62.5 \mathrm{wt} . \%$. As a result, it was considered that the mixed surfactant formed the separated state between two models.

Figure 3 shows full width at half maximum (FWHM) values of the specimens. In the region of P-123/(Brij-76 + P123) from 0 to 37.5 wt.\%, FWHM values slightly increased, so it indicated that XRD peaks became broad. In other words, it implies that ordering of the pores decreased. The reason is that the insufficient amount of surfactant cannot make micelles, and it influences on the formation of the structure of micelles and the development of the micelles of another kind of surfactant negatively [24, 25]. Therefore, the formation of the micelle structure was hindered by the minor surfactant of P-123. Similarly, in region of P123/(Brij-76 + P-123) from 62.5 to $100 \mathrm{wt} . \%$, hindrance of the minor surfactant of Brij-76 occurred, and ordering of the pores decreased as $\mathrm{P}-123 /(\mathrm{Brij}-76+\mathrm{P}-123)$ went down from 100 to $62.5 \mathrm{wt} . \%$. However, in the region of P-123/(Brij$76+$ P-123) from 37.5 to $62.5 \mathrm{wt} . \%$, FWHM value rapidly

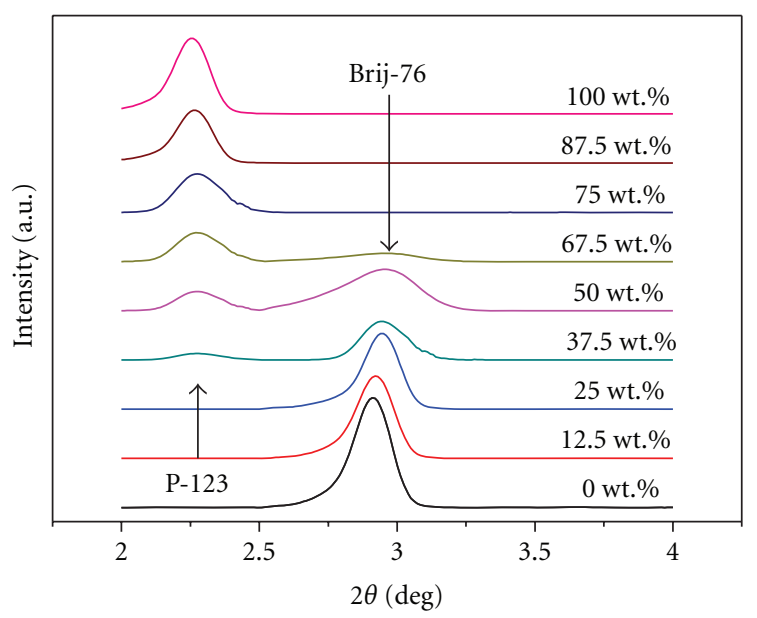

FIGURE 2: XRD patterns of mesoporous silica film along the weight ratio of mixed surfactant (P-123/(Brij-76 + P-123)).

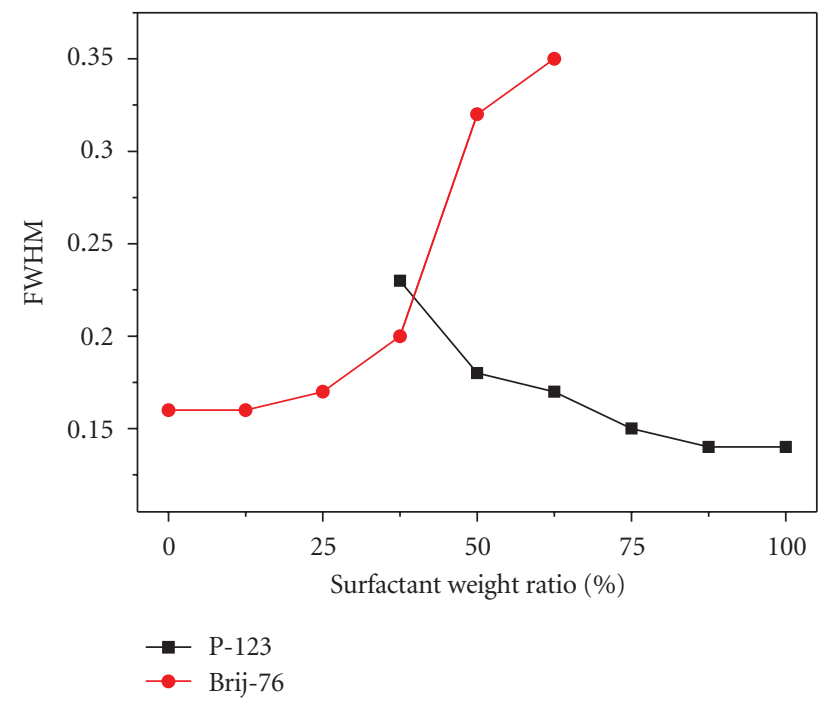

FIGURE 3: FWHM of mesoporous silica film along the mass ratio of mixed surfactants (P-123/(Brij-76 + P-123)).

increased, and XRD peaks became very broad. That means each kind of surfactant was enough to make two kinds of its own micelles, so two kinds of micelles formed each pore structure and hindered each other. That is, micelles hindered the formation of micelle structure, not surfactants. It was considered that the reason about the change of the FWHM value was based on the difference of hindrance between micelle and surfactant.

Figure 4 shows the porosity of ordered mesoporous silica film according to the weight ratio of mixed surfactant (P-123/(Brij-76 + P-123)). The porosity decreased in the region of $\mathrm{P}-123 /(\mathrm{Brij}-76+\mathrm{P}-123)$ from 0 to $50.0 \mathrm{wt} . \%$ and increased in the region of P-123/(Brij-76 + P-123) from 50.0 to $100 \mathrm{wt} \%$ slightly. It indicates that the small amount of another kind of surfactant cannot contribute to porosity because the small number of surfactants cannot make micelles and only interrupt the pore structure. In case 


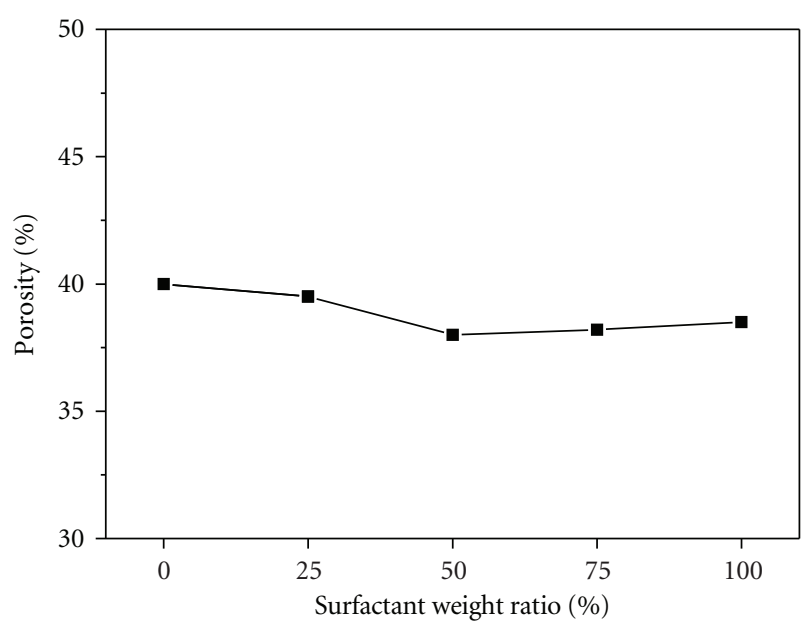

Figure 4: Porosity of mesoporous silica film along the weight ratio of mixed surfactants (P-123/(Brij-76 + P-123)).

of P-123/(Brij-76 + P-123) of $50.0 \mathrm{wt} . \%$, the porosity is the lowest value. This is because two kinds of micelles formed each pore structure and hindered each other as mentioned above. It was also confirmed by XRD peaks in Figure 2. Thus, it implies that pore structure in case of P-123/(Brij-76 + P123 ) of $50.0 \mathrm{wt} \%$ is less ordered than in case of P-123/(Brij$76+\mathrm{P}-123)$ of 0 or $100 \mathrm{wt} . \%$. However, taken as a whole, it was not considerable change of the porosity, so we could conclude that most of the added surfactant participated in the formation of pores, and the porosity depended on the total amount of surfactants regardless of the kind of surfactant.

To confirm a mixed pore structure obtained from XRD result of mesoporous silica film with $50 \mathrm{wt}$ \% P-123/(Brij$76+$ P-123) in Figure 2, the microstructure was observed through TEM measurement and given in Figure 5. Two different domains, highly ordered mesostructure and low ordered mesostructure, were observed in TEM image of the film. The interpore distance of highly ordered mesostructure was about $3.3 \mathrm{~nm}$, and that of low ordered mesostructure was about $4.7 \mathrm{~nm}$. The highly ordered mesostructure corresponds to the domain formed by Brij-76, and the low ordered mesostructure corresponds to the domain formed by P-123 when comparing with XRD results. The interpore distances in the TEM images were larger than those in XRD results. This enlargement in the TEM images could be caused by a diffused image of pores from a misorientation between a pore alignment direction and an electron beam incident direction. However, the interpore distance ratios of two kinds of pore structure were similar, for example, 1.3 with XRD and 1.4 with TEM. Therefore, it could be concluded that the mesoporous silica film could have a mixed two different pore structures when using two different surfactants such as Brij76 and $\mathrm{P}-123$.

\section{Conclusions}

Ordered mesoporous silica films were synthesized using mixed surfactant, Brij-76 and P-123. Two kinds of mixed

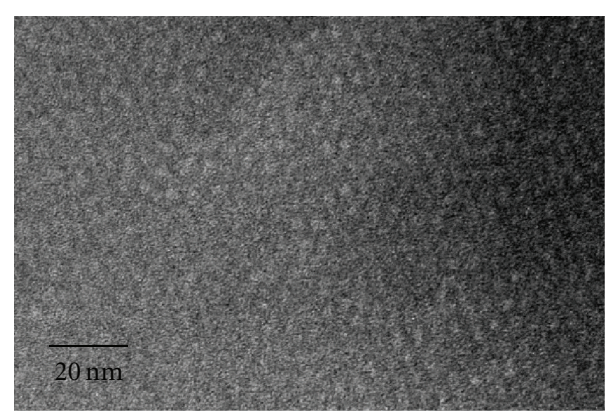

(a)

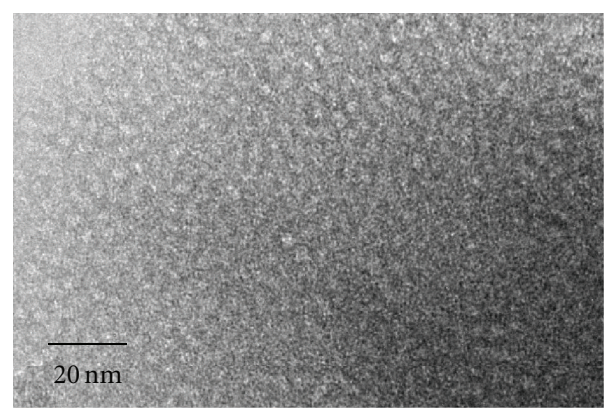

(b)

Figure 5: Microstructures of mesoporous silica film with the composition of 50 wt.\% (P-123/(Brij-76 + P-123)); (a) the domain formed by Brij-76, and (b) the domain formed by P-123.

pore structures, nonseparated state and separated state, were expected to be formed. The mixture of two ordered pore structures is possible in case of the separated state, and surfactants which have very different $\mathrm{cmc}$ are needed. Results of XRD pattern showed the mixture of ordered pore structure in the region of $\mathrm{P}-123 /($ Brij-76 + P-123) from 37.5 to $62.5 \mathrm{wt} . \%$. XRD peaks of ordered pore structure became broad due to hindrance by surfactant and/or micelle. The porosity depended on the total amount of surfactants regardless of the kind.

\section{Acknowledgments}

This study was supported by a grant from the Fundamental R\&D Program for Core Technology of Materials funded by the Ministry of Knowledge Economy, Republic of Korea. Experiments at PLS were supported in part by MEST and POSTECH.

\section{References}

[1] J. Rouquerol, D. Avnir, C. W. Fairbridge et al., "Recommendations for the characterization of porous solids (Technical Report)," Pure and Applied Chemistry, vol. 66, p. 1739, 1994.

[2] V. Chiola, J. E. Ritsko, and C.D. Vanderpool, Process for producing low-bulk density silica, U.S. Patent 3556725, 1971.

[3] S. Inagaki, S. Ogata, Y. Goto, and Y. Fukushima, "Mesoporous materials derived from layered silicates and the adsorption properties," Studies in Surface Science and Catalysis, vol. 117, pp. 65-76, 1998. 
[4] R. Ryoo, J. M. Kim, C. H. Ko, and C. H. Shin, "Disordered molecular sieve with branched mesoporous channel network," Journal of Physical Chemistry, vol. 100, no. 45, pp. 17718 17721, 1996.

[5] S. E. Park, "Application of Mesoporous Molecular Sieves," Chemistry World, vol. 38, no. 11, pp. 30-39, 1998.

[6] C. T. Kresge, M. E. Leonowicz, W. J. Roth, J. C. Vartuli, and J. S. Beck, "Ordered mesoporous molecular sieves synthesized by a liquid-crystal template mechanism," Nature, vol. 359, no. 6397, pp. 710-712, 1992.

[7] Y. Lu, R. Ganguli, C. A. Drewien et al., "Continuous formation of supported cubic and hexagonal mesoporous films by sol-gel dip-coating," Nature, vol. 389, no. 6649, pp. 364-368, 1997.

[8] R. Nagarajan, Structure-Performance Relationships in Surfactants, part 1.1, Marcel Dekker, New York, NY, USA, 2003.

[9] S. P. Moulik, "Micelles: self-organized surfactant assemblies," Current Science, vol. 71, no. 5, pp. 368-376, 1996.

[10] N. Igarashi, K. A. Koyano, Y. Tanaka, S. Nakata, K. Hashimoto, and T. Tatsumi, "Investigation of the factors influencing the structural stability of mesoporous silica molecular sieves," Microporous and Mesoporous Materials, vol. 59, no. 1, pp. 4352, 2003.

[11] J. S. Choi, D. J. Kim, S. H. Chang, and W. S. Ahn, "Catalytic applications of MCM-41 with different pore sizes in selected liquid phase reactions," Applied Catalysis A, vol. 254, no. 2, pp. 225-237, 2003.

[12] R. L. Putnam, N. Nakagawa, K. M. McGrath et al., "Titanium dioxide-surfactant mesophases and Ti-TMS1," Chemistry of Materials, vol. 9, no. 12, pp. 2690-2693, 1997.

[13] D. Zhao, J. Feng, Q. Huo et al., "Triblock copolymer syntheses of mesoporous silica with periodic 50 to 300 angstrom pores," Science, vol. 279, no. 5350, pp. 548-552, 1998.

[14] J. R. Matos, M. Kruk, L. P. Mercuri et al., "Ordered mesoporous silica with large cage-like pores: structural identification and pore connectivity design by controlling the synthesis temperature and time," Journal of the American Chemical Society, vol. 125, no. 3, pp. 821-829, 2003.

[15] A. Doyle and B. K. Hodnett, "Stability of MCM-48 in aqueous solution as a function of $\mathrm{pH}$," Microporous and Mesoporous Materials, vol. 63, pp. 53-57, 2003.

[16] L. Z. Wang, J. L. Shi, J. Yu, W. H. Zhang, and D. S. Yan, "Temperature control in the synthesis of cubic mesoporous silica materials," Materials Letters , vol. 45, no. 5, pp. 273-278, 2000.

[17] L. Chen, J. Xu, W. H. Zhang, J. D. Holmes, and M. A. Morris, "Syntheses of complex mesoporous silicas using mixtures of nonionic block copolymer surfactants: understanding formation of different structures using solubility parameters," Journal of Colloid and Interface Science, vol. 353, no. 1, pp. 169180, 2011.

[18] S.-B. Jung, T.-J. Ha, J.-B. Seon, and H.-H. Park, "Phase behavior of ordered mesoporous silica film prepared by Brij76 block copolymer," Microporous and Mesoporous Materials, vol. 111, no. 1-3, pp. 188-193, 2008.

[19] M. Yan, S. Dourdain, and A. Gibaud, "Analysis of water condensation in P123 templated 2D hexagonal mesoporous silica films by X-ray reflectivity," Thin Solid Films, vol. 516, no. 22, pp. 7955-7961, 2008.

[20] P. K. Kipkemboi, P. C. Kiprono, and P. Kndalut, "Preparation of mesoporous silica with amphiphilic poly(oxyethylene)/ poly(oxybutylene) diblock and poly(oxyethylene)/poly(oxypropylene) triblock copolymers as templates," Indian Journal of Chemistry-Section A, vol. 48, no. 4, pp. 498-503, 2009.

[21] T.-J. Ha, H.-H. Park, S.-Y. Jung, S.-J. Yoon, J.-S. Kim, and H.W. Jang, "Effect of porosity on the Seebeck coefficient of mesoporous $\mathrm{TiO}_{2}$ thin films," Thin Solid Films, vol. 518, no. 24, pp. 7196-7198, 2010.

[22] S. K. Hait and S. P. Moulik, "Determination of critical micelle concentration (CMC) of nonionic surfactants by donoracceptor interaction with iodine and correlation of $\mathrm{CMC}$ with hydrophile-lipophile balance and other parameters of the surfactants," Journal of Surfactants and Detergents, vol. 4, no. 3, pp. 303-309, 2001.

[23] Y. L. Su and H. Z. Liu, "Temperature-dependent solubilization of PEO-PPO-PEO block copolymers and their application for extraction trace organics from aqueous solutions," Korean Journal of Chemical Engineering, vol. 20, no. 2, pp. 343-346, 2003.

[24] F. Y. Wei, Z. W. Liu, J. Lu, and Z. T. Liu, "Synthesis of mesoporous MCM-48 using fumed silica and mixed surfactants," Microporous and Mesoporous Materials, vol. 131, no. 1-3, pp. 224-229, 2010.

[25] C. Liu, S. Wang, Z. Rong, X. Wang, G. Gu, and W. Sun, "Synthesis of structurally stable MCM-48 using mixed surfactants as co-template and adsorption of vitamin B12 on the mesoporous MCM-48," Journal of Non-Crystalline Solids, vol. 356, no. 25-27, pp. 1246-1251, 2010. 

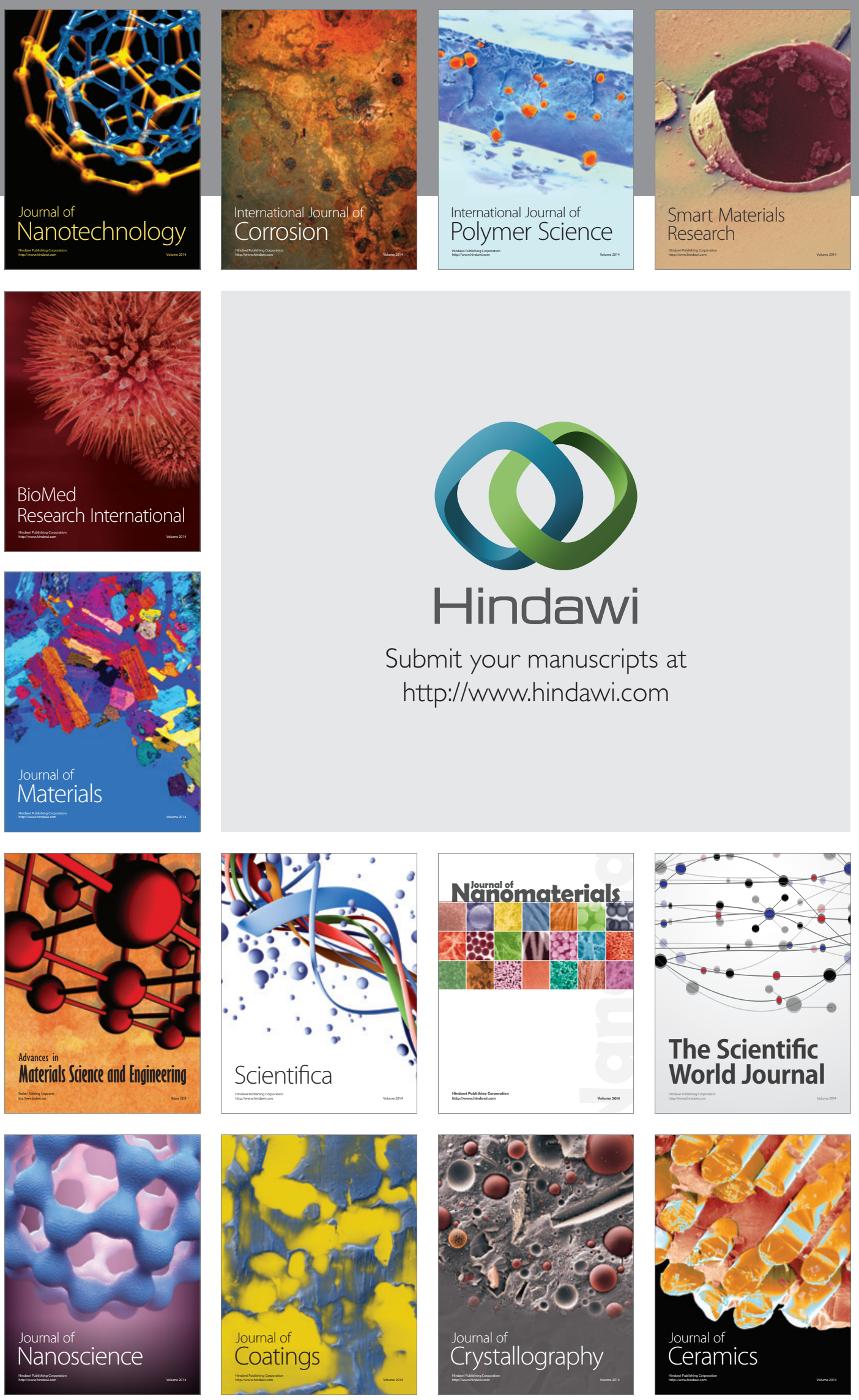

The Scientific World Journal

Submit your manuscripts at

http://www.hindawi.com

\section{World Journal}

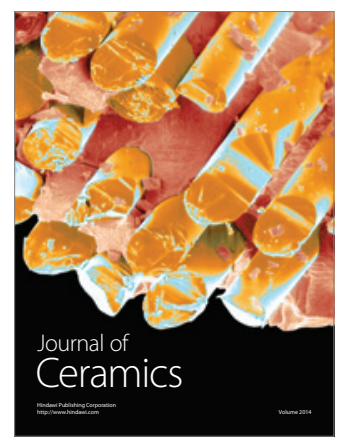

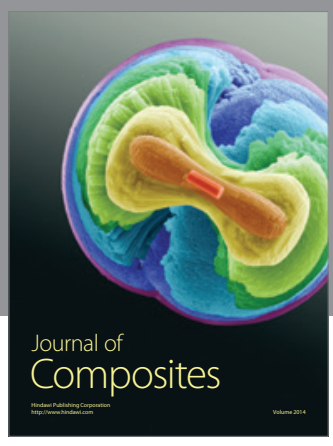
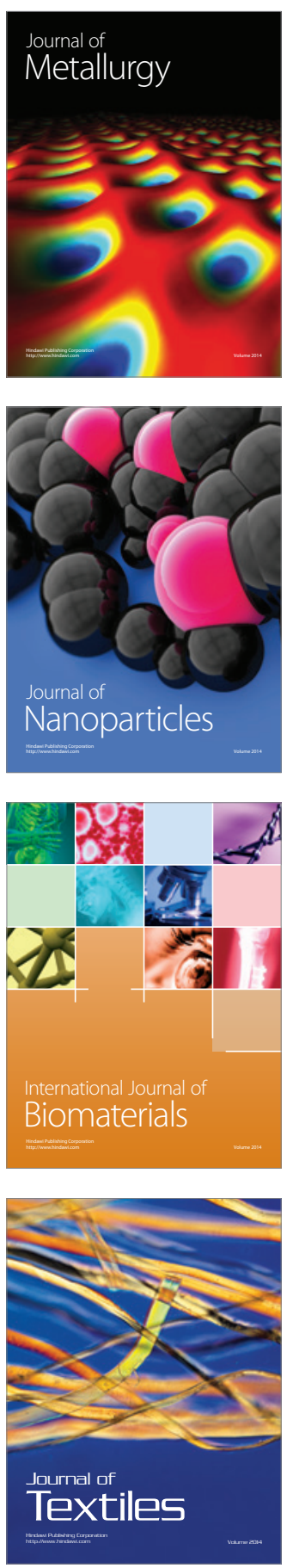